\section{Whose baby are you?}

SIR - It is almost inevitable for parents to be told that their babies look just like them, but the people who suggest this to the pleased parents have the advantage of already knowing that these are their children. Without this advantage, can people pick the correct progenitors from sets of possible parents? Our experiments provide two answers: children in general do not look enough like their parents for a resemblance to be detected, with the one exception that one-year-olds look like their fathers.

Subjects were shown pictures of offspring, and rated the similarity between each of them and three possible mothers or fathers, one of whom was the actual parent (Fig. 1). Subjects performed this task for both male and female children at ages one, ten and twenty years. They also rated the similarity between children at these three ages, and between pictures of parents taken when their children were one and twenty.

The subjects were very accurate at

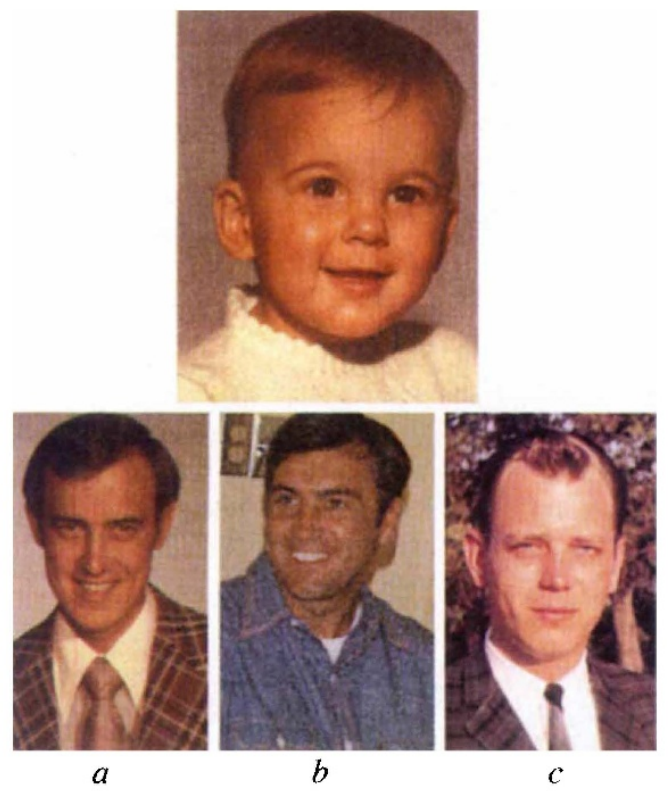

FIG. 1 Twenty-four Caucasian families provided a photograph of a child at age one year, a photograph of the mother and one of the father, both taken when they were one year old. Twelve of the children are now adults, allowing us additionally to gather photographs of the child at 10 and 20 and a recent photograph of the parents. Twelve sets with boys and twelve with girls were obtained. Subjects rated the resemblance between the three ages of offspring and sets of possible parents, between the children at the three ages, and between the parents at different ages. They compared each stimulus picture with three possible matches, one of which was a true match. They rated the resemblance between the stimuli and each of the possible matches on a 0-10 scale of increasing resemblance. In all, 122 subjects participated, and each possible match was rated by 18-21 of these raters. The order of the stimulus pictures, the three possible matches, and the three child ages were counterbalanced. The figure shows an example of a one-year-old and three possible fathers. The correct match is $b$. detecting the similarities between the pictures of the parents taken 20 years apart (Fig. 2a). The children were also recognizable from one age to another, indicating that the pictures were of high enough quality for their individual characteristics to be visible. Males and females ere equally recognizable over time.

The 20- and 10-year-old children were no more similar to their actual mothers and fathers than to random parents Fig. 2b). One-year-olds could not be matched to their mothers. In fact, the only reliable similarity was between oneyear-olds (both girls and boys) and their athers.

Children in general do not look enough ike their parents to allow judges who do not already know of the relationship to spot the resemblance. Assertions that children look just like their parents could be due to a desire to please the parents, picking just the features that randomly how some resemblance, or commenting only the offspring who happen to be similar. Alternatively, resemblance could depend on characteristics that still pictures cannot capture.

There may be an evolutionary rationale for the unique resemblance between one-year-olds and their fathers. While a mother can be quite sure that the baby is hers, no matter what it looks like, the father cannot. It could then be to a baby's advantage to look like the father, to encourage paternal investment. Daly and Wilson ${ }^{1}$ argue that people are biased to say there is a resemblance between children and fathers to reassure the dads. They collected evidence that mothers, fathers, relatives and friends think babies look more like their father than their mother and suggest that these subjective reports are due to an evolutionarily advantageous bias, never considering that they may be accurate. (It is also the case that the evolutionary pressure should be to make the baby look more like the father than other men, not more like the father than the mother. Babies who simply look masculine are no reassurance to nervous fathers.) Finegan and Mackenzie $^{2}$ have also reported that babies look more like their fathers than their mothers, although not more like unrelated men than unrelated women.

Because both male and female babies can be matched to the father, it is not simple sex-linked inheritance. One possibility is that
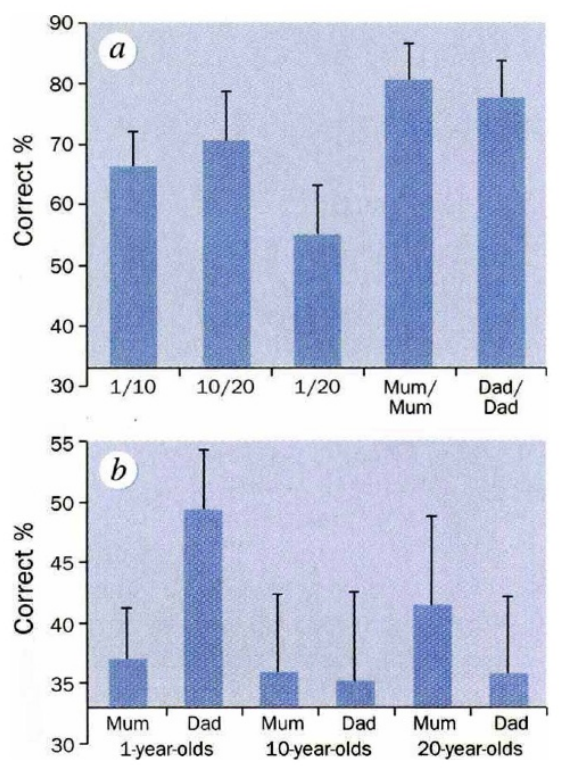

FIG. 2 The percentage of subjects who gave the correct match the highest rating was computed for each stimulus, and these scores were com pared with the chance level of $33.3 \%$. a, The raters could match: one-year-olds to themselves at $10(66.3 \%, t(11)=5.64, P<0.0005), 10-y r$ olds to themselves at $20(70.6 \%, t(11)=4.62$, $P<0.001)$, one-year-olds to themselves at 20 $(55.0 \%, t(11)=2.62, P<0.05)$, mothers to themselves at ages separated by $19 \mathrm{yr}(80.6 \%$, $t(11)=8.0, P<0.0001)$, and fathers to themselves $(77.6 \%, t(11)=7.2, P<0.0001) . b$, The only significant familial resemblance was reported between one-year-olds and their fathers $(49.2 \%, t(23)=3.21, P<0.005)$. This ability to pick out the biological fathers was true for both baby boys $(50.5 \%)$ and baby girls $(48.0 \%)$, and was essentially as good as the ability to match these infants to themselves at 20 .

the variability of babies' faces is more similar to the variability of fathers' faces than of mothers'. Features that distinguish women from each other, such as cheekbone prominence, may not help with baby identification, because they are obscured on their faces, while the features that are salient on men might be visible on one-year-olds. Another possibility is that the facial morphology of a baby is more determined by the father than by the mother. Differential maternal and paternal gene expression has been documented, with DNA methylation possibly playing a role in such 'genomic imprinting ${ }^{3}$. It may be to a mother's advantage for the expression of her genes to be limited in determining the appearance of a child if it causes the father to recognize the infant and care for it.

Nicholas J. S. Christenfeld

Emily A. Hill

Department of Psychology, University of California, San Diego,

La Jolla, California 92093, USA

1. Daly, M. \& Wilson, M. I. Ethot. Sociobiol. 3, 69-78 (1982).

2. Finegan, J. E. \& Mackenzie, A. Can. Psychol. 31, 300 (1990).

3. Li, E., Beard, C. \& Jaenisch, R. Nature 366, 362-364 (1993). 